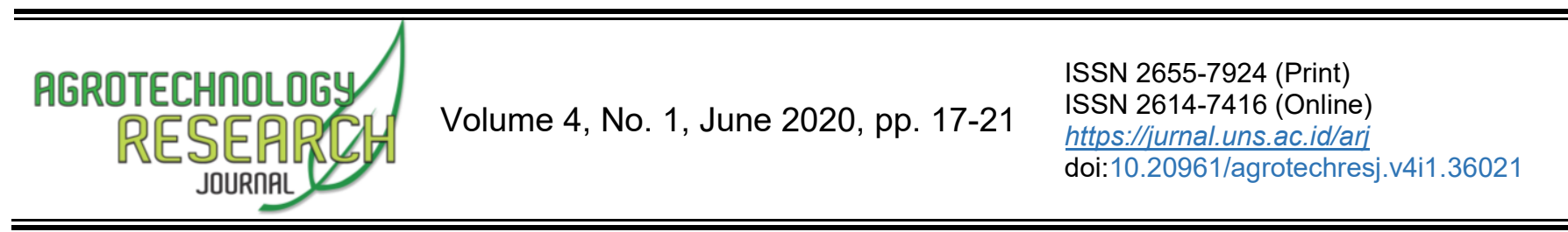

\title{
Pemanfaatan Lahan Pasca Tambang Timah dengan Budidaya Sawi
}

\author{
Tri Lestari ${ }^{*}$, Rion Apriyadi ${ }^{2}$, Dewi Ratna Ulfa ${ }^{3}$ \\ ${ }^{1-3}$ Faculty of Agriculture, Fisheries and Biology, Universitas Bangka Belitung, Bangka, Indonesia
}

Received 27 November 2019; Accepted 14 May 2020; Published 25 June 2020

\section{ABSTRACT}

Culture crop technology with ameliorant and mulch can fulfill nutrients to improve growth of mustard on post tin mining land. This research aimed to know the effect of various ameliorant and mulch for growth of mustard on post tin mining land. The method used was experimental method with factorial completely randomize design with four replications. First factor was type of ameliorant, consist of compost, and cow manure. The second factor was type of mulch, consist of no mulch, reed mulch, and black silver plastic mulch. The results showed that type of ameliorant significantly affected number of leave, root volume, root wet weight and root dry weight. Type of mulch significantly affected plant height, number of leave, shoot wet weight and root dry weight. Interaction of ameliorant and mulch significantly affected plant height, number of leave, root volume, shoot wet weight, root wet weight and root wet weight. Compost with black silver plastic mulch tended to give better results for growth of mustard on post tin mining land.

Keywords: Ameliorant; Growth of Mustard; Mulch

Cite This As (CSE Style): Lestari T, Apriyadi R, Ulfa DR. 2020. Pemanfaatan Lahan Pasca Tambang Timah dengan Budidaya Sawi. Agrotech Res J 4(1): 17-21. https://doi.org/10.20961/agrotechresj.v4i1.36021

\section{PENDAHULUAN}

Lahan pasca tambang timah merupakan lahan kritis yang banyak tersebar di wilayah Pulau Bangka. Sukarman et al. (2008) menyatakan bahwa Pulau Bangka memiliki lahan pasca tambang timah seluas 79.163 ha, terdiri dari lahan darat seluas 70.176 ha atau $89,80 \%$ dari luas Pulau Bangka. Aktivitas tambang timah menyebabkan penurunan kualitas lahan baik sifat fisik, kimia maupun biologi tanah antara lain lahan didominasi tailing dengan lanskap tidak beraturan; kelas tekstur didominasi pasir; tingkat kesuburan tanah tergolong sangat rendah; $\mathrm{pH}$ tanah sangat masam; kadar $\mathrm{C}$ organik, hara N, P, K, Kapasitas Tukar Kation (KTK) dan Kejenuhan Basa (KB) sangat rendah (Asmarhansyah 2016).

Sifat fisik, kimia dan biologi tanah pada lahan pasca tambang timah kurang baik, sehingga perlu dilakukan perbaikan dan pemulihan lahan menjadi lahan pertanian produktif yang dikelola secara tepat dan maksimal. Pengelolaan lahan pasca tambang timah dapat dilakukan melalui penggunaan amelioran. Menurut Purba (2015), amelioran atau pembenah tanah merupakan bahan yang ditambahkan ke dalam tanah untuk memperbaiki sifat fisik, kimia dan biologi tanah di lingkungan akar tanaman.

Menurut Gedoan et al. (2011) bahwa amelioran kotoran sapi dapat meningkatkan produksi biji dan

\section{*Corresponding Authors:}

${ }^{1}$ E-Mail: trilestari25sm07@gmail.com kandungan minyak tanaman jarak pagar di lahan pasca tambang timah. Penelitian lainnya yang dilakukan oleh Rusli et al. (2016) menunjukkan bahwa aplikasi pembenah tanah kompos dan/atau tanah liat menghasilkan pertumbuhan tanaman karet yang optimal pada lahan bekas tambang timah. Selain mengubah sifat fisik, kimia dan biologi tanah, aktivitas tambang timah juga mengubah mikroklimat lingkungan tanah. Lahan pasca tambang timah mengalami penurunan kelembaban tanah sekitar $10 \%$ dan peningkatan temperatur tanah $2-10^{\circ} \mathrm{C}$ yang tidak mendukung bagi pertumbuhan tanaman dan mikroorganisme tanah (Nurtjahya et al. 2008). Upaya memodifikasi mikroklimat lingkungan tanah dapat dilakukan melalui penggunaan mulsa. Penggunaan mulsa berperan menjaga dan melindungi keadaan mikroklimat (Pangaribuan 2009), mencegah kehilangan air dari tanah sehingga temperatur dan kelembaban tanah relatif stabil (Mahmudi et al. 2017), serta menciptakan kondisi lingkungan tanah yang baik bagi aktivitas mikroorganisme.

Penelitian yang dilakukan oleh Irawati et al. (2017) menunjukkan bahwa aplikasi mulsa plastik hitam perak pada tanaman pakcoy memberikan berat segar tajuk dan berat segar akar paling tinggi dibandingkan dengan aplikasi mulsa lainnya. Penelitian lainnya yang dilakukan oleh Dika et al. (2017) bahwa perlakuan mulsa plastik perak gerenjeng pada tanaman brokoli memiliki komponen hasil bobot segar bunga tertinggi daripada perlakuan tanpa mulsa.

Penanaman komoditas pertanian pada lahan pasca tambang timah perlu dilakukan secara selektif melalui 
pemilihan komoditas yang bernilai ekonomis tinggi (Iskandar et al. 2020). Komoditas pertanian yang dapat dikembangkan di lahan pasca tambang timah seperti padi, palawija, hortikultura (sayuran dan buah-buahan), serta perkebunan (Asmarhansyah 2016). Pakcoy merupakan salah satu jenis sayuran daun kelompok kubis-kubisan yang bernilai ekonomis tinggi, karena memiliki harga jual lebih mahal daripada jenis sawi lainnya, umur panen relatif pendek dan hasilnya memberikan keuntungan memadai (Inonu et al. 2014).

Berdasarkan permasalahan di lahan pasca tambang timah, sehingga upaya untuk pemanfaatan lahan marginal tersebut perlu adanya modifikasi lingkungan dan penambahan organik salah satunya dengan amelioran. Penelitian ini bertujuan untuk mengkaji pengaruh penggunaan amelioran dan mulsa terhadap pertumbuhan tanaman pakcoy (Brassica chinensis L.) di lahan pasca tambang timah. Penelitian ini diharapkan dapat menjadi salah satu strategi pengelolaan lahan pasca tambang timah sebagai lahan pertanian produktif.

\section{BAHAN DAN METODE}

Penelitian ini dilaksanakan di lahan pasca tambang timah Desa dwi Makmur, Kecamatan Merawang, Bangka, Indonesia pada bulan April-Mei 2019. Rancangan yang digunakan adalah rancangan acak lengkap (RAL) faktorial dengan 2 faktor yaitu jenis amelioran dan jenis mulsa. Faktor pertama yaitu jenis amelioran yang terdiri dua taraf yaitu: kompos (A1) dan pupuk kotoran sapi (A2). Faktor kedua yaitu jenis mulsa terdiri tiga taraf yaitu: tanpa mulsa (M0), mulsa alangalang (M1), dan mulsa plastik hitam perak (M2).

Pelaksanaan penelitian dimulai dari membersihkan lahan dari gulma, kemudian menggemburkan dan meratakan dengan cangkul dan garu. Luas lahan yang digunakan, yaitu $8,1 \times 5,5 \mathrm{~m}^{2}$. Bedengan dibuat berukuran $1 \mathrm{~m} \times 1 \mathrm{~m} \times 30 \mathrm{~cm}$ dengan jarak antar bedengan $30 \mathrm{~cm}$. Setiap lubang tanam terdiri dari satu bibit tanaman dengan jarak tanam $30 \mathrm{~cm} \times 30 \mathrm{~cm}$. Persemaian dilakukan di dalam polybag menggunakan media topsoil dan kompos/kotoran sapi (2:1). Amelioran berupa kompos dan kotoran sapi diberikan dengan masing-masing dosis $405 \mathrm{~g} /$ lubang tanam (45 ton/ha). Pemberian amelioran dilakukan sebelum aplikasi mulsa pada saat penanaman, yakni dengan cara dibenam pada lubang tanam. Pemberian mulsa dilakukan setelah aplikasi amelioran pada saat penanaman. Mulsa organik (alang-alang) dikeringkan di bawah sinar matahari selama 7 hari, lalu dihamparkan di atas bedengan dengan ketebalan $3 \mathrm{~cm}$, sedangkan mulsa kimia-sintetis (Mulsa Plastik Hitam Perak/MPHP) yang telah terbentuk lubang tanam sesuai jarak tanam.

Peubah yang diamati meliputi: tinggi tanaman, jumlah daun, warna daun, kandungan klorofil, volume akar, bobot basah tajuk, bobot kering tajuk, bobot basah akar, bobot kering akar, nisbah tajuk akar, dan kandungan vitamin C. Data hasil penelitian dianalisis menggunakan uji $\mathrm{F}$ dengan tingkat kepercayaan 95\%, jika terdapat perlakuan yang memberikan pengaruh nyata terhadap peubah yang diamati, maka dilakukan uji lanjut Beda Nyata Terkecil (BNT) dengan tingkat kepercayaan 95\%. Analisis data menggunakan program Statistical Analysis System (SAS).

\section{HASIL DAN PEMBAHASAN}

Hasil penelitian menunjukkan bahwa amelioran berpengaruh terhadap jumlah daun, volume akar, bobot basah akar dan bobot kering akar. Penggunaan mulsa juga berpengaruh terhadap jumlah daun, bobot kering akar, tinggi tanaman dan bobot basah tajuk. Kombinasi amelioran dengan mulsa berpengaruh terhadap jumlah daun, volume akar, bobot kering akar, tinggi tanaman, bobot basah tajuk dan bobot basah akar. Hal ini dikarenakan bahan organik yang bersumber dari bahan pembenah tanah yang berbeda akan memberikan respon yang berbeda pula terhadap tanaman. Menurut Yarda et al. (2019) bahwa amelioran dapat memperbaiki sifat-sifat tanah tailing pasir tambang timah sehingga mampu mendukung pertumbuhan tanaman sawi. Sondakh et al. (2018) menyatakan bahwa amelioran dapat menyediakan hara untuk kebutuhan tanaman.

Hasil uji lanjut BNT pengaruh penggunaan amelioran (Tabel 1) menunjukkan bahwa perlakuan kompos berbeda nyata dengan perlakuan kotoran sapi pada jumlah daun, volume akar, bobot basah akar dan bobot kering akar. Kompos merupakan amelioran yang memberikan pengaruh terbaik terhadap pertumbuhan tanaman pakcoy di lahan pasca tambang timah. Hal ini disebabkan karena kompos berasal dari bahan baku yang terdiri dari percampuran berbagai bahan organik sehingga menghasilkan komposisi unsur hara dengan jenis yang beragam dan jumlah yang banyak. Harizena (2012) menyatakan bahwa amelioran dari berbagai bahan organik dapat mempercepat laju dekomposisi selama pengomposan dan meningkatkan kandungan unsur hara dari amelioran yang dihasilkan. Kompos mengandung 1,62 \% N, 2,33 \% $\mathrm{P}_{2} \mathrm{O}_{5}, 3,00 \% \mathrm{~K}_{2} \mathrm{O}, 1,72$ $\% \mathrm{CaO}$ dan $1,53 \% \mathrm{MgO}$, yakni memiliki kandungan unsur hara yang lebih tinggi daripada kotoran sapi.

Tabel 1. Hasil uji lanjut BNT pengaruh penggunaan amelioran terhadap pertumbuhan dan hasil

\begin{tabular}{lcccc}
\hline \multirow{2}{*}{ Amelioran } & \multicolumn{4}{c}{ Peubah yang diamati } \\
\cline { 2 - 5 } & $\begin{array}{c}\text { Jumlah } \\
\text { daun }\end{array}$ & $\begin{array}{c}\text { Volume } \\
\text { akar }\end{array}$ & $\begin{array}{c}\text { Bobot } \\
\text { basah akar }\end{array}$ & $\begin{array}{c}\text { Bobot } \\
\text { kering akar }\end{array}$ \\
\hline Kompos & $17,25 \mathrm{a}$ & $3,36 \mathrm{a}$ & $2,07 \mathrm{a}$ & $0,76 \mathrm{a}$ \\
Kotoran sapi & $13,98 \mathrm{~b}$ & $1,94 \mathrm{~b}$ & $1,39 \mathrm{~b}$ & $0,53 \mathrm{~b}$
\end{tabular}

Keterangan: Angka yang diikuti oleh huruf yang berbeda pada kolom yang sama menunjukkan berbeda nyata pada uji lanjut BNT $\alpha=5 \%$.

Hasil uji lanjut BNT pengaruh penggunaan mulsa (Tabel 2) menunjukkan bahwa penggunaan mulsa alang-alang menunjukkan pertumbuhan dan hasil tertinggi. Hal ini disebabkan karena mulsa alang-alang berasal dari bahan yang dapat terurai sehingga dapat meningkatkan kandungan bahan organik pada tanah. Menurut Sutiya et al. (2012), kandungan kimia pada alang-alang terdiri dari a-selulosa $40,22 \%$, holoselulosa $59,62 \%$, hemiselulosa/pentosan $18,40 \%$ dan lignin $31,29 \%$. Suhastyo and Raditya (2019) menyatakan bahwa mol dari daun kelor mengandung berbagai senyawa yang akan diuraikan oleh mikroorganisme sehingga unsur hara yang dilepaskan akan menjadi tersedia untuk tanaman sawi pagoda. 
Tabel 2. Hasil uji lanjut BNT pengaruh penggunaan mulsa terhadap pertumbuhan dan hasil

\begin{tabular}{lcccc}
\hline \multirow{2}{*}{ Mulsa } & \multicolumn{4}{c}{ Peubah yang diamati } \\
\cline { 2 - 5 } & $\begin{array}{c}\text { Tinggi } \\
\text { tanaman }\end{array}$ & $\begin{array}{c}\text { Jumlah } \\
\text { daun }\end{array}$ & $\begin{array}{c}\text { Bobot } \\
\text { basah } \\
\text { tajuk }\end{array}$ & $\begin{array}{c}\text { Bobot } \\
\text { kering } \\
\text { akar }\end{array}$ \\
\hline Tanpa mulsa & $13,79 \mathrm{~b}$ & $12,40 \mathrm{c}$ & $22,04 \mathrm{~b}$ & $0,47 \mathrm{~b}$ \\
$\begin{array}{l}\text { Alang-alang } \\
\text { Plastik hitam }\end{array}$ & $16,23 \mathrm{a}$ & $18,50 \mathrm{a}$ & $40,04 \mathrm{a}$ & $0,68 \mathrm{a}$ \\
perak (MPHP) & $15,11 \mathrm{ab}$ & $15,95 \mathrm{~b}$ & $30,75 \mathrm{ab}$ & $0,78 \mathrm{a}$ \\
\hline
\end{tabular}

Keterangan: Angka yang diikuti oleh huruf yang berbeda pada kolom yang sama menunjukkan berbeda nyata pada uji lanjut BNT $\alpha=5 \%$.

Yunus et al. (2015) menambahkan bahwa senyawasenyawa yang terbentuk dari proses penguraian dalam aktivitas biologi tanah akan menyebabkan kemantapan struktur tanah menjadi meningkat, aerasi menjadi lebih baik dan permeabilitas tanah yang tinggi terpelihara. Pengaruh mulsa alang-alang dan mulsa plastik hitam perak tidak berbeda nyata terhadap tinggi tanaman, jumlah daun, bobot basah tajuk dan kerat kering akar. Hal ini disebabkan oleh jenis mulsa yang berbeda akan memberikan pengaruh yang berbeda pula bagi tanaman.

Hasil uji lanjut BNT interaksi antara penggunaan amelioran dan mulsa (Tabel 3) menunjukkan bahwa perlakuan kompos + mulsa plastik hitam perak memberikan peningkatan sebesar $14.27 \%$ pada peubah tinggi tanaman, volume akar, bobot basah akar dan bobot kering akar dibandingkan tanpa menggunakan mulsa. Perlakuan kompos + mulsa alang-alang memberikan peningkatan sebesar $29.75 \%$ pada peubah jumlah daun dibandingkan tanpa menggunakan mulsa. Perlakuan kotoran sapi + mulsa alang-alang memberikan peningkatan sebesar $60.9 \%$ pada peubah bobot basah tajuk dibandingkan tanpa menggunakan mulsa. Hasil penelitian Yarda et al. (2019) menunjukkan penggunaan mulsa yang dikombinasikan dengan ameliorant memberikan pertumbuhan tanaman sawi lebih baik dibandingkan dengan tanpa mulsa di lahan pasca tambang timah.
Kompos + mulsa plastik hitam perak memberikan hasil terbaik pada tinggi tanaman, volume akar, bobot basah akar dan bobot kering akar. Hal ini dikarenakan mulsa plastik hitam perak dapat meningkatkan aktivitas mikroorganisme dalam menguraikan unsur hara pada kompos sehingga tanaman mampu menyerap unsur hara dan melangsungkan proses fotosintesis secara optimal. Gunadi and Sulastrini (2013) menyatakan bahwa pada bagian bawah mulsa yang berwarna hitam dapat menyerap cahaya matahari yang memengaruhi kondisi lingkungan di sekitar perakaran pertanaman. Irawati et al. (2017) menambahkan bahwa warna hitam dari mulsa sangat efektif dalam mengendalikan gulma, karena gulma tidak mendapatkan cahaya matahari untuk berfotosintesis. Apabila perkecambahan dan pertumbuhan gulma terhambat, maka tanaman dapat tumbuh dan berkembang dengan baik. Selain itu, mulsa plastik hitam perak dapat meningkatkan penyerapan cahaya matahari oleh tanaman sehingga proses fotosintesis berjalan lebih cepat dan fotosintat terbentuk lebih banyak. Muslim and Soelistyono (2017) mengemukakan bahwa pada bagian atas mulsa (menghadap ke atmosfer) berwarna perak dapat memantulkan cahaya matahari yang memengaruhi kondisi lingkungan mikro di sekitar pertanaman. Menurut Fahrurrozi et al. (2009), pantulan cahaya oleh warna perak mulsa mampu mengurangi pemanasan berlebihan ke zona rizosfer dan juga mengurangi populasi serangga, karena serangga mengikuti arah pantulan tersebut dan meninggalkan zona pertanaman yang diusahakan.

Kompos + mulsa alang-alang memberikan hasil terbaik pada jumlah daun. Hal ini disebabkan karena alang-alang dapat memberikan tambahan unsur hara pada tanah. Lasmini et al. (2018) menyatakan bahwa semakin meningkat bahan organik pada tanah, maka semakin menurun kepadatan tanah sehingga perakaran tanaman dapat berkembang dengan leluasa membentuk sistem perakaran yang baik. Pertumbuhan akar yang baik akan meningkatkan pergerakan hasil fotosintesis ke bagian atas tanaman sehingga pertumbuhan tajuk akan menghasilkan jumlah daun yang lebih banyak (Lubis et al. 2017).

Tabel 3. Hasil uji lanjut BNT interaksi amelioran dan mulsa terhadap pertumbuhan dan hasil

\begin{tabular}{|c|c|c|c|c|c|c|}
\hline \multirow{2}{*}{$\begin{array}{l}\text { Kombinasi } \\
\text { perlakuan }\end{array}$} & \multicolumn{6}{|c|}{ Peubah yang diamati } \\
\hline & Tinggi tanaman & Jumlah daun & Volume akar & Bobot basah tajuk & Bobot basah akar & Bobot kering akar \\
\hline $\begin{array}{l}\text { Kompos tanpa } \\
\text { mulsa }\end{array}$ & $14,29 a b c$ & $14,05 \mathrm{c}$ & $2,67 \mathrm{bc}$ & 27,25 abc & $1,84 a b$ & $0,59 \mathrm{bc}$ \\
\hline $\begin{array}{l}\text { Kompos + mulsa } \\
\text { alang-alang }\end{array}$ & $15,94 a b$ & 20,00 a & $3,33 \mathrm{ab}$ & $37,00 \mathrm{ab}$ & $2,05 a b$ & $0,79 a b$ \\
\hline Kompos + MPHP & $16,67 \mathrm{a}$ & $17,70 \mathrm{ab}$ & $4,09 a$ & 39,92 a & $2,32 \mathrm{a}$ & $0,90 \mathrm{a}$ \\
\hline $\begin{array}{l}\text { Kotoran sapi tanpa } \\
\text { mulsa }\end{array}$ & $13,28 \mathrm{c}$ & $10,75 d$ & $1,67 \mathrm{c}$ & $16,84 \mathrm{c}$ & $0,98 \mathrm{c}$ & $0,35 \mathrm{c}$ \\
\hline $\begin{array}{l}\text { Kotoran sapi }+ \\
\text { mulsa alang-alang }\end{array}$ & $16,52 \mathrm{a}$ & $17,00 \mathrm{~b}$ & $2,25 \mathrm{c}$ & 43,09 a & $1,35 \mathrm{bc}$ & $0,57 \mathrm{bc}$ \\
\hline $\begin{array}{l}\text { Kotoran sapi + } \\
\text { MPHP }\end{array}$ & $13,55 \mathrm{bc}$ & $14,20 \mathrm{c}$ & $1,92 \mathrm{c}$ & $21,58 \mathrm{bc}$ & $1,86 a b$ & $0,66 a b$ \\
\hline
\end{tabular}

Keterangan: Angka yang diikuti oleh huruf yang berbeda pada kolom yang sama menunjukkan berbeda nyata pada uji lanjut BNT $\alpha=5 \%$. 
Kotoran sapi + mulsa alang-alang memberikan hasil terbaik pada bobot basah tajuk. Hal ini disebabkan karena kotoran sapi dan mulsa alang-alang memiliki kandungan serat (selulosa) yang dapat mengikat air lebih kuat sehingga air tersedia bagi pertumbuhan tanaman. Menurut Widyasmara et al. (2012), feses sapi mengandung selulosa sebesar $25,2 \%$, hemiselulosa $18,6 \%$, lignin $20,2 \%$, nitrogen $1,67 \%$, fosfat $1,11 \%$ dan kalium $0,56 \%$. Kusumawati et al. (2015) menyatakan bahwa bobot basah tanaman menunjukkan kandungan air dalam jaringan tanaman. Kandungan air dalam jaringan tanaman tersebut tergantung pada kemampuan tanaman menyerap air dari lingkungan dan daya dukung lingkungan dalam proses penyerapan air. Semakin banyak kandungan air, maka semakin tinggi bobot basah tanaman.

Kompos + mulsa plastik hitam perak memberikan hasil bobot kering tajuk tertinggi. Hal ini disebabkan karena mulsa plastik hitam perak memiliki permukaan bawah berwarna hitam yang dapat meningkatkan konsentrasi karbon dioksida di zona pertanaman sehingga dapat meningkatkan pula laju fotosintesis. Panggabean and Wardati (2015) mengemukakan bahwa bobot kering tanaman sangat dipengaruhi oleh optimalnya proses fotosintesis. Bobot kering yang terbentuk mencerminkan banyaknya fotosintat sebagai hasil fotosintesis, karena bahan kering sangat tergantung pada laju fotosintesis. Semakin meningkat laju fotosintesis, maka semakin tinggi bobot kering tanaman (Fitrianah et al. 2012). Hasil penelitian Lestari et al. (2020) menunjukkan penggunaan bahan organik yang bersumber dari limbah kelapa sawit dapat meningkatkan pertumbuhan dan produksi tanaman nenas di lahan pasca tambang timah. Agus et al. (2019), menyatakan teknologi yang tepat guna untuk merehabilitasi ekosistem lahan bekas tambang timah di kawasan tropis berfungsi sebagai paru-paru dunia untuk semua kehidupan di planet bumi.

\section{KESIMPULAN}

1. Penggunaan kompos memberikan pengaruh peningkatan jumlah daun tanaman pakcoy sebesar $25.5 \%$ dibandingkan menggunakan kotoran sapi di lahan pasca tambang timah.

2. Penggunaan mulsa alang-alang cenderung memberikan pengaruh peningkatan jumlah daun sebesar $33.3 \%$ dan bobot basah tajuk tanaman pakcoy sebesar $44.95 \%$ dibandingkan tanpa mulsa di lahan pasca tambang timah.

3. Penggunaan kompos dan mulsa alang-alang cenderung memberikan interaksi terbaik terhadap pertumbuhan jumlah daun tanaman pakcoy di lahan pasca tambang timah.

\section{UCAPAN TERIMAKASIH}

Terima kasih disampaikan kepada PT. Timah Tbk selaku mitra dalam penelitian ini.

\section{DAFTAR PUSTAKA}

Agus C, Hendryan A, Harianja V, Faridah E, Atmanto $W D$, Cahyanti $P A B$, Wulandaric $D$, Pertiwiningrum $A$, Suhartanto B, Bantara I, et al. 2019. Role of organic soil amendment of paramagnetic humus and compost for rehabilitation of post tin-mined tropical land. Int $\mathrm{J}$ Smart Grid Clean Energy. 8(5):556-561. doi:10.12720/sgce.8.5.556-561.

Asmarhansyah. 2016. Karakteristik dan Strategi Pengelolaan lahan bekas tambang timah di kepulauan bangka belitung asmarhansyah. Pros Semin Nas Inov Teknol Pertan Banjarbaru.(1):14231430. doi:10.1017/CBO9781107415324.004.

Dika M, Utomo C, Suryanto A, Medha D. 2017. Penggunaan berbagai jenis mulsa untuk meningkatkan produksi brokoli (Brassica oleracea L.). J Produksi Tanam. 5(1):100-107.

Fahrurrozi, Tarmizi I, Hermawan B. 2009. Evaluasi berbagai dosis nitrogen untuk teknik produksi tanaman cabai yang menggunakan mulsa. J Bionatura. 11(2):147-154.

Fitrianah L, Fatimah S, Hidayati Y. 2012. Pengaruh komposisi media tanam terhadap pertumbuhan dan kandungan saponin pada dua varietas tanaman gendola ( Basella sp ). Agrovigor. 5(1):34-47.

Gedoan SP, Hartana A, Hamim H, Widyastuti U, Sukarno N. 2011. Pertumbuhan tanaman jarak pagar (Jatropha curcas L.) Pada lahan pasca tambang timah di bangka yang diberi pupuk organik. J IImu Sains. 15(1):181. doi:10.35799/jis.11.2.2011.205.

Gunadi N, Sulastrini I. 2013. Penggunaan Netting House dan Mulsa Plastik untuk Meningkatkan Pertumbuhan dan Hasil Tanaman Cabai Merah (The Use of Netting House and Plastic Mulch to Increase the Growth and Yield of Hot Peppers). J Hortik. 23(1):36-46.

Harizena IND. 2012. Pengaruh jenis dan dosis mol terhadap kualitas kompos sampah rumah tangga. [skripsi] Fakultas Pertanian, Universitas Udayana.

Inonu I, Khodijah NS, Supriadi A. 2014. Budidaya pakchoy ( Brassica rapa L .) di lahan tailing pasir bekas penambangan timah dengan amelioran pupuk organik dan pupuk npk pakchoy ( Brassica rapa $L$.) cultivation in sandytailings of tin post- miningsite with organic manure and NPK fertilizer amel. J Lahan Suboptimal. 3(1):76-82.

Irawati H, Purbajanti ED, Sumarsono S, Fatchullah D. 2017. Penggunaan macam mulsa dan pola jarak tanam terhadap pertumbuhan dan produksi Pakchoy (Brassica rapa chinensis I.). J Agro Complex. 1(3):78. doi:10.14710/joac.1.3.78-84.

Iskandar $\mathrm{H}$, Hasanuddin $\mathrm{U}$, Syamsu JA, Hasanuddin U. 2020. Tinjauan reklamasi lahan pasca tambang timah (Sn) melalui penanaman tumbuhan pakan. Pros Semin Nas "Membangun Sumber Daya Peternak di Era Revolusi Ind 40".(May):39-47. 
Kusumawati K, Muhartini S, Rogomulyo R. 2015. Pengaruh konsentrasi dan frekuensi pemberian limbah tahu terhadap pertumbuhan dan hasil bayam (Amaranthus tricolor L.) pada media pasir pantai. Vegetalika. 4(2):48-62. doi:10.22146/veg.9274.

Lasmini SA, Wahyudi I, Rosmini. 2018. Aplikasi Mulsa dan Biokultur Urin Sapi terhadap Pertumbuhan dan Hasil Bawang Merah. J Hortikultura Indonesia. 9(2):103-110. doi:10.29244/jhi.9.2.103-110.

Lestari T, Apriyadi R, Mustikarini ED, Saputra W, Merlin Y. 2020. The application of palm-oil waste as organic materials on three pineapple accessions cultivated on post-tin mining land in Bangka Island, Indonesia. Nusant Biosci. 12(1):40-45. doi:10.13057/nusbiosci/n120107.

Lubis PA, Tyasmoro SY, Sudiarsono. 2017. Pengaruh jenis dan ketebalan mulsa dalam mempertahankan kandungan air tanah dan dampaknya terhadap tanaman kedelai (Glycine max (L.) di lahan kering. Produksi Tanam. 5(5):791-798.

Mahmudi S, Rianto H, Historiawati. 2017. Pengaruh mulsa plastik hitam perak dan jarak tanam pada hasil bawang merah ( Allium cepa fa . ascalonicum , L .) varietas biru lancor. J IImu Pertan Trop dan Subtrop. 2(2):60-62.

Muslim M, Soelistyono R. 2017. The effect of silver black plastic mulch with various form and high of seedbed on growth of cauliflower (Brassica oleracea var . Botrytis L .). J Agric Sci. 2(2):85-90.

Nurtjahya E, Agustina F, Putri WAE. 2008. Neraca ekologi penambangan timah di Pulau Bangka studi kasus pengalihan fungsi lahan di ekosistem darat. $J$ Biol Res. 14(1):29-38. doi:10.23869/bphjbr.14.1.20085.

Pangaribuan HPD. 2009. Kajian pola tanam tumpangsari selada crop-tomat dan mulsa jerami pada pertumbuhan dan hasil tanaman. J Penelit Pertan Terap. 10(1):1-6.

Panggabean P, Wardati. 2015. Effect of liquid organic fertilizer and compost rind cocoa to the growth of oil palm seedlings (Elaeis gueneensis Jacq.) in the main nursery. JOM Faperta. 2(2):1115-1135.
Purba R. 2015. Kajian pemanfaatan amelioran pada lahan kering dalam meningkatkan hasil dan keuntungan usahatani kedelai. Prosiding Seminar Nasional Masyarakat Biodiversitas Indonesia. 1 (2): 1483-1486. doi:10.13057/psnmbi/m010638.

Rusli, Ferry Y, Hafif B, Wardiana E. 2016. The Effectiveness of Ameliorants, Fertilizer, and Mycorrhiza for Rubber Growth At Post Tin Mining Land. J TIDP 3(3):175-184.

Sondakh TD, Sumampow DMF, Polii MGM. 2018. Perbaikan sifat fisik dan kimia tailing melalui pemberian amelioran berbasis bahan organik. Eugenia. doi:10.35791/eug.23.3.2017.18965.

Suhastyo AA, Raditya FT. 2019. Respon pertumbuhan dan hasil sawi pagoda (Brassica narinosa) terhadap pemberian mol daun kelor. Agrotechnology Res J. 3(1):56. doi:10.20961/agrotechresj.v3i1.29064.

Sukarman, Rusmin D, Melati. 2008. Pengaruh lokasi produksi dan lama penyimpanan terhadap mutu jahe muda (Zingiber officinale Rosc.). J Penelit Tanam Ind. 14(3):119-124.

Sutiya B, Istikowati WT, Rahmadi A. 2012. Kandungan kimia dan sifat serat alang-alang ( Imperata cylindrica ) sebagai gambaraN. Bioscientiae. 9 (1):8-19.

Widyasmara L, Pratiwiningrum A, Yusiati LM. 2012. Pengaruh jenis kotoran ternak sebagai substrat dengan penambahan serasah daun jati (Tectona grandis) terhadap karakteristik biogas pada proses fermentasi. Bul Peternak. 36(1):40. doi:10.21059/buletinpeternak.v36i1.1275.

Yarda VRD, Lestari T, Pratama D. 2019. Application of mulch and palm oil waste as bioremediation agents in post mining land. IOP Conf Ser Earth Environ Sci. 353(1). doi:10.1088/1755-1315/353/1/012021.

Yunus F, Hasanah U, Anshar M. 2015. Pengaruh pemberian sungkup plastik dan mulsa terhadap dinamika kadar air , suhu tanah dan produksi bawang merah ( Allium ascalonicum L .) pada tanah beririgasi teknis. J Agroland. 22(1):33-40. 